\title{
The Impact of Transferring Stroke Patients: An Analysis of National Administrative Data
}

\author{
Charlotte Zerna, Noreen Kamal, M. Patrice Lindsay, Jiming Fang, Michael D. Hill
}

\begin{abstract}
Background: Interhospital transfer is an important but resource-intensive pattern of care. The use for stroke patients is highly dependent upon health system structure. We examined the impact of hospital transfers for stroke care in Canada. Methods: We analyzed hospital administrative data within the Canadian Institute for Health Information (CIHI) Database for the 3 fiscal years 2011/12, 2012/13 and 2013/14. Patients with clinical stroke syndrome (ischemic or hemorrhagic) were identified using International Classification of Diseases. Stroke centers were defined by Heart \& Stroke Foundation of Canada stroke report. Results: During the 3-year period,397 patients in Canada (excluding Quebec) were admitted to hospital for clinical stroke syndrome. Median age was 75 (interquartile range [IQR] 64-84) years; 50.6 \% were male. Less than $5 \%(n=4030)$ of patients were transferred. Patients transferred to stroke centers were younger $(\mathrm{p}<0.001)$ and had shorter median length of stay $(\mathrm{p}<0.001)$. The highest probability of discharge home was associated with sole care at stroke center $(43.8 \%)$. Transfer to stroke center from community hospital had the highest probability for discharge to rehabilitation facility (25\%) and lowest to either long-term (2.1\%) or complex community care (2.0\%). Transferred patients had lower mortality at discharge. Conclusion: Younger patients were transferred more frequently to stroke centers; older patients were more likely treated in community hospitals. Sole stroke center care was associated with high discharge rate to home; transfer to a stroke center was associated with high discharge rate to rehabilitation and lower mortality rates.
\end{abstract}

RÉSUMÉ: L'impact du transfert de patients victimes d'un accident vasculaire cérébral : une analyse de données administratives pancanadiennes. Contexte: Le transfert d'un patient vers un autre hôpital constitue une avenue thérapeutique notable qui exige néanmoins beaucoup de ressources. Dans le cas de patients victimes d'un accident vasculaire cérébral (AVC), une telle avenue demeure fortement tributaire des structures d'un système de santé. Nous voulons donc examiner l'impact des transferts hospitaliers sur les soins prodigués à des patients canadiens victimes d'un AVC. Méthodes: Nous avons analysé des données clinico-administratives récoltées par l'Institut canadien d'information sur la santé (ICIS). Ces données concernent les années budgétaires 2011-2012, 2012-2013 et 2013-2014. Des patients chez qui on avait diagnostiqué un syndrome clinique lié à un AVC, qu'il soit de nature ischémique ou hémorragique, ont été sélectionnés au moyen de la Classification statistique internationale des maladies. La notion de « centre de soins complets de l'AVC » a quant à elle été définie par la Fondation des maladies du cœur et de l'AVC dans un de ses rapports. Résultats: Durant cette période de trois ans, 397 patients du Canada (à l'exclusion du Québec) ont été hospitalisés en raison d'un syndrome clinique lié à un AVC. Leur âge moyen était de 75 ans (écart interquartile de 64 - 84) tandis que 50,6\% d'entre eux étaient de sexe masculin. Au total, moins de 5\% (n = 4030) des patients ont été transférés. Ceux l'ayant été vers des centres de soins complets de l'AVC étaient plus jeunes ( $\mathrm{p}<0,001)$; la durée médiane de leur séjour était aussi plus courte ( $\mathrm{p}<0,001)$. La probabilité la plus élevée d'obtenir un congé pour retourner à la maison était associée aux centres de soins complets de l'AVC $(43,8 \%)$. Un transfert d'un hôpital communautaire vers un centre de soins complets de l'AVC était aussi associé à une probabilité plus élevée d'obtenir un congé à destination d'un établissement de réadaptation (25\%) mais aussi à une probabilité plus basse de l'être vers des soins de longue durée $(2,1 \%)$ ou des soins communautaires de nature complexe $(2,0 \%)$. Enfin, les patients transférés donnaient à voir un plus faible taux de mortalité à la suite d'un congé. Conclusions: Les patients moins âgés étaient transférés moins fréquemment à des centres de soins complets de l'AVC. De leur côté, les patients plus âgés étaient plus susceptibles d'être soignés dans des hôpitaux communautaires. Seuls les centres de soins complets de l'AVC étaient associés à un taux élevé de congés à destination du domicile tandis que les transferts vers des centres de soins complets de l'AVC étaient associés à un taux élevé de congés vers des services de réadaptation ainsi qu'à des taux de mortalité inférieurs.

doi:10.1017/cjn.2016.285

Can J Neurol Sci. 2016; 43: 760-764

\section{BACKGROUND}

Although stroke demographics are changing with the aging of western populations, stroke continues to be a significant socioeconomic burden causing disability, and remains the second leading cause of death worldwide. ${ }^{1-3}$ Factors such as hospital type, patient demographics, and stroke type have been shown to

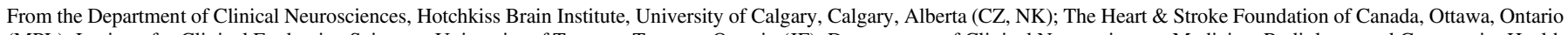

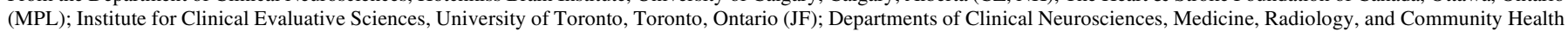
Sciences, Hotchkiss Brain Institute, University of Calgary, Calgary, Alberta (MDH).

Received February 8, 2016. Final Revisions Submitted May 6, 2016. Date of Acceptance May 25, 2016.

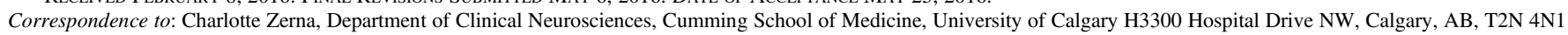
CANADA. Email: Charlotte.Zerna@albertahealthservices.ca 
affect in-hospital mortality and discharge destination. ${ }^{4,5}$ Whereas patient demographics and stroke type are not modifiable, transfer of patients to differently equipped hospitals might influence the patient's outcome. Transfers within the hyperacute phase can offer advanced treatment options such as endovascular therapy or neurosurgical intervention or, in the subacute phase, patients can return to local community hospitals from higher levels of care.

We analyzed the characteristics and outcomes, by stroke type, of Canadian patients who were and were not transferred between hospitals as part of their acute stroke care.

\section{Methods}

We performed a population-based retrospective cohort study of all stroke patients admitted to hospital, using data from the Canadian Institutes for Health Information (CIHI), a non-profit organization that collects universally available health care information from 28 pan-Canadian databases. The CIHI's Discharge Abstract Database (DAD) contains demographic, administrative and clinical data (including deaths and transfers) on all inpatient hospital discharges. Health services are administered by each of Canada's ten provinces and three territories. All hospitals in those provinces and territories (with the exception of Quebec) are required to report to the DAD; Quebec reports their data through DAD but does not allow it to be shared. ${ }^{6}$ Coding of stroke in the DAD is known to have high sensitivity and specificity, and because all acute care hospitals in Canada provide universal access to the Canadian population the data are nationally comprehensive. ${ }^{7}$

We analyzed hospital administrative data for the fiscal years 2011/12 through 2013/14 from the DAD. Patients were identified using International Classification of Diseases 10 (ICD-10) codes for acute stroke, including transient ischemic attack (TIA) (G45. $\mathrm{x}$ ), ischemic stroke (I63.x, I64.x), aneurysmal subarachnoid hemorrhage (I60.x), and intracerebral hemorrhage (I61.x). Stroke risk factors (hypertension, diabetes mellitus and atrial fibrillation) and comorbid illness were identified by ICD-10 code and by their calculated Charlson-Deyo index (grouped 0-1 vs. 2+).

Based on the Heart and Stroke Foundation (HSF) 2014 Stroke Report and the Canadian Stroke Best Practice Recommendations, all hospitals were categorized into four peer groups based on availability of services and resources for stroke care: Comprehensive Stroke Services, Advanced Stroke Services, Basic Stroke Services and General Healthcare Providers. ${ }^{89}$ Advanced and Comprehensive Stroke Services provide access to intravenous thrombolysis and have stroke teams that can be mobilized to rapidly assess, diagnose and implement management strategies to reduce the risk of stroke recurrence or poor outcomes. Comprehensive Stroke Services have a stroke unit, regional support services and a department of neurosurgery. They may also have endovascular interventionists' service. Advanced Stroke Services do not have a stroke unit and may or may not have a department of neurosurgery. Basic Stroke Services have neuroimaging capability (i.e., a CT scanner on site), do not offer intravenous thrombolysis or other organized stroke care, but in some cases offer basic prevention services. Organizations that are considered General Health Providers do not have neuroimaging capability. HSF Canada provided a list of assigned peer group for every hospital; linkage to individual patient records was then conducted at CIHI before data were anonymized and provided to HSF Canada for analysis. Comprehensive and Advanced Stroke Services were merged to "stroke center" and Basic Stroke Services and General Health Provider were merged to "community hospital".

A randomly generated unique identifier was assigned to each case by CIHI to allow for tracking patients across multiple admissions or transfers. We defined an interhospital transfer as follows: any admission within 6-48 hours of the previous discharge where the "institution from" matches the "institution to" unique identifier (meaning one case of care) and any admissions within 12 hours of the previous discharge where either the "institution from" or the "institution to" type equals 1 (meaning acute care). This definition excludes readmission to the same institution within that time frame. Discharge location categories were: home without services; home with homecare services; inpatient rehabilitation; other acute care facility; complex continuing care; long term care; died and other. Discharge locations were used as outcome parameters.

Measures of central tendency and measures of variability were calculated according to standard descriptive statistics. We used multivariable logistic regression models to test whether sex or stroke type were associated with transfer to a comprehensive stroke center. We included the following variables in our model: province, age, stroke type and cardiovascular risk factors (namely atrial fibrillation, coronary artery disease, diabetes mellitus, hypertension, previous stroke/transient ischemic attack) according to past medical history. All analyses were conducted with the use of SAS software (SAS Institute Inc, Cary, NC). All reported p-values are two-sided.

\section{Results}

During the fiscal years $2011 / 12$ to $2013 / 14,84,397$ patients were admitted to hospital for stroke syndromes (ischemic stroke, transient ischemic attack, intracerebral hemorrhage, subarachnoid hemorrhage). Data were incomplete in $2.8 \%$ of patients. The flowchart of the study population is shown in Figure 1. Less than $5 \%(\mathrm{n}=4030)$ of patients were transferred between community hospitals and stroke centers in either direction. The proportion of patients transferred by province/territory was: $11.5 \%$ in the Territories, $9.2 \%$ in Saskatchewan, $7.7 \%$ in Prince Edward Island, $6.2 \%$ in Manitoba, $5.9 \%$ in British Columbia and Nova Scotia, $4.8 \%$ in Alberta, $3.9 \%$ in Ontario, $3.3 \%$ in Newfoundland and $2.5 \%$ in New Brunswick.

Patients transferred to stroke centres had a significantly lower median age. Baseline characteristics of transferred and nontransferred patients are displayed in Table 1. Increasing age was associated with a reduced probability of transfer: $7.6 \%$ in the $<45$ year old, $6.0 \%$ in the $45-64$ year old, $5.2 \%$ in the $65-74$ year old, $4.4 \%$ in the $75-84$ year old and $3.1 \%$ in the $>85$ year old. By stroke type, $12.0 \%$ of subarachnoid hemorrhages, $6.3 \%$ of intracerebral hemorrhages, $4.9 \%$ of ischemic strokes and $1.1 \%$ of transient ischemic attacks were transferred. The median total length of stay (including both the transferring and receiving facilities) was 6 (3-14) days for non-transferred patients compared to 18 (9-38) days in patients who did get transferred $(\mathrm{P}<.0001)$. The median length of stay for different transfer pathways is shown in Table 2.

Detailed results regarding discharge destinations for transferred and non-transferred patients are displayed in Table 3. The highest probability of discharge to home was associated with sole care at a stroke center $(43.8 \%)$. Transfer to a stroke center from community hospital was associated with the highest probability for discharge to rehabilitation facility $(25 \%)$ and the 


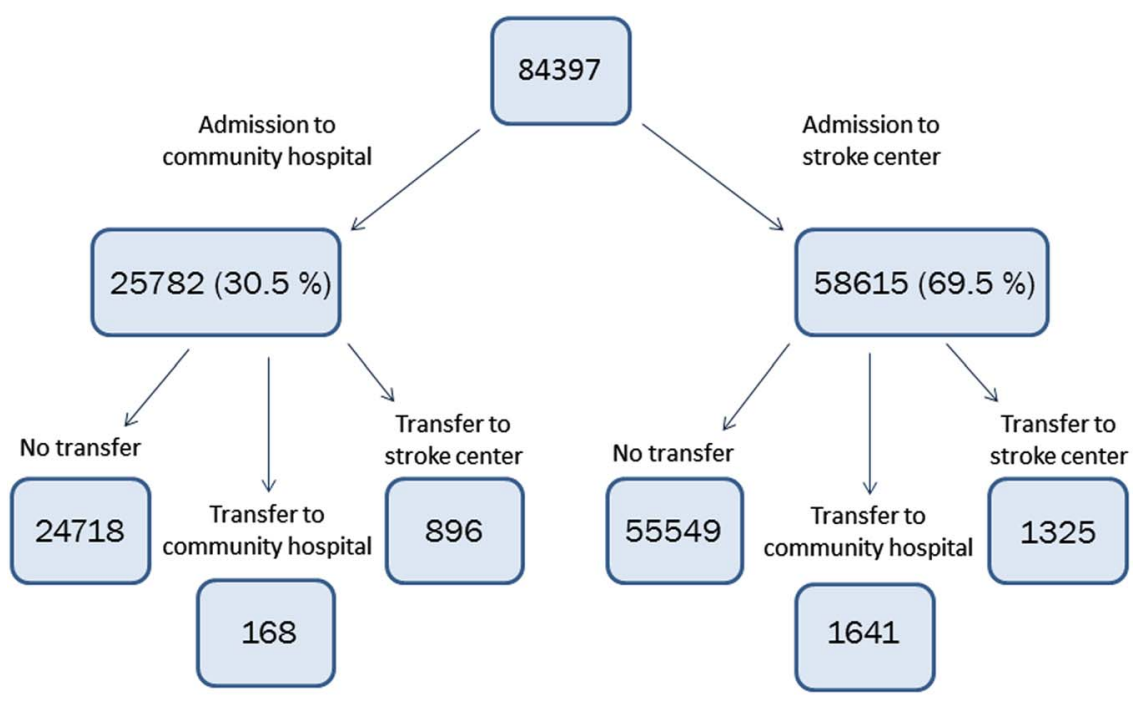

Figure 1: Flowchart of study population.

lowest one to either long-term $(2.1 \%)$ or community care center (2.0\%). Transferred patients were less likely to die $(13.3 \%$ vs. $14.8 \%$, risk ratio [RR] $0.905,95 \%$ confidence interval [CI] 0.835-0.981, $\mathrm{p}=0.015$ ). Discharge destinations for transferred patients divided by specific transfer pathway are reported in Table 4.

Multivariable regression analysis showed no difference for transfer to a comprehensive stroke center between males and females (odds ratio [OR] 1.03, $\mathrm{CI}_{95}$ 0.94-1.11). Patients with intracerebral hemorrhages (OR 1.37, $\left.\mathrm{CI}_{95} 1.21-1.56\right)$ and subarachnoid hemorrhages (OR 3.39, $\mathrm{CI}_{95}$ 2.98-3.85) were more likely to be transferred to a stroke center compared to patients with ischemic strokes.

Table 1: Clinical characteristics

\begin{tabular}{l|c|c|r}
\hline & Transferred & Not transferred & $P$ value \\
\hline Total, n (\%) & $4030(4.8)$ & $80367(95.2)$ & \\
\hline Female, n (\%) & $1896(47)$ & $39829(49.6)$ & 0.002 \\
\hline age, years, median (IQR) & $71(59-81)$ & $76(64-84)$ & $<0.001$ \\
\hline Ischemic stroke, n (\%) & $2796(69.4)$ & $54739(68.1)$ & 0.092 \\
\hline TIA, n (\%) & $151(3.7)$ & $13337(16.6)$ & $<0.001$ \\
\hline ICH, n (\%) & $588(14.6)$ & $8709(10.8)$ & $<0.001$ \\
\hline SAH, n (\%) & $495(12.3)$ & $3582(4.5)$ & $<0.001$ \\
\hline cardiovascular risk factors: & & & \\
\hline Hypertension, n (\%) & $2278(56.5)$ & $45543(56.7)$ & 0.858 \\
\hline Diabetes, n (\%) & $953(23.6)$ & $21572(26.8)$ & $<0.001$ \\
\hline Atrial fibrillation, n (\%) & $720(17.9)$ & $14458(18.0)$ & 0.841 \\
\hline Previous stroke, $\mathrm{n}(\%)$ & $366(9.1)$ & $8142(10.1)$ & 0.031 \\
\hline Charles-Deyo-Index $>2, \mathrm{n}(\%)$ & $1670(41.4)$ & $34532(43.0)$ & 0.056 \\
\hline P & \multicolumn{3}{|c}{}
\end{tabular}

$P$ values are Pearson's chi-square test (2-tailed). IQR indicates interquartile range, TIA transient ischemic attack, ICH intracerebral hemorrhage, SAH subarachnoid hemorrhage.

\section{DiscuSSION}

Our study provides evidence that stroke center care is associated with better discharge destination outcomes, a surrogate for final clinical outcome. Sole stroke center care was associated with a high discharge rate to home; transfer to a stroke center was associated with a high discharge rate to rehabilitation facilities and lower mortality rates. A potential explanation is the younger age and lesser comorbidity of the transferred patients with the subsequent stroke unit care (life-saving, sparing large number of severely disabled life years) resulting in better outcomes.

Transfer to a stroke center was initiated faster than transfer to a community hospital when comparing median length of stay in days at the first facility. A possible explanation is that these patients were transferred for (hyper)acute treatment whereas a transfer to a community hospital is likely to represent repatriation to the home community. Common practice is to transfer patients back to their home community, especially those waiting for longterm care beds, rather than take up beds in comprehensive centers. The median length of total stay was prolonged for all transferred patients, perhaps due to higher symptom severity and thus development of complications.

The overall rate of transfers was low, at less than five percent. This is probably the result of multiple factors. First, acute transfer of ischemic stroke (the most common stroke type) for

Table 2: Median length of stay

\begin{tabular}{l|c|c}
\hline Transfer pathway & $\begin{array}{c}\text { Median length } \\
\text { of stay, } \\
\text { first facility, } \\
\text { days (IQR) }\end{array}$ & $\begin{array}{c}\text { Median length } \\
\text { of stay, } \\
\text { total, } \\
\text { days (IQR) }\end{array}$ \\
\hline Community hospital to community hospital & $6.5(2-14)$ & $20(9-42.5)$ \\
\hline Community hospital to stroke centre & $2(1-5)$ & $12(7-22)$ \\
\hline Stroke centre to community hospital & $7(3-15)$ & $22(10-45)$ \\
\hline Stroke centre to stroke centre & $4(1-12)$ & $19(9-39)$ \\
\hline
\end{tabular}

IQR indicates interquartile range 


\section{Table 3: Discharge destinations}

\begin{tabular}{|c|c|c|c|c|c|}
\hline Discharge destination & Transferred total $=4030 \mathrm{n}(\%)$ & Not transferred total $=80367 \mathrm{n}(\%)$ & $\mathbf{R R}$ & $95 \% \mathrm{CI}$ & $P$ value \\
\hline Home & $1285(31.9)$ & $33985(42.3)$ & 0.754 & $0.720-0.789$ & $<0.001$ \\
\hline Rehabilitation & $821(20.1)$ & $11656(14.5)$ & 1.405 & $1.319-1.496$ & $<0.001$ \\
\hline Community care centre & $213(5.3)$ & $3627(4.5)$ & 1.171 & $1.024-1.340$ & 0.213 \\
\hline Home care & $345(8.6)$ & $8982(11.2)$ & 0.766 & $0.691-0.849$ & $<0.001$ \\
\hline Long-term care facility & $194(4.8)$ & $4621(5.2)$ & 0.837 & $0.728-0.963$ & 0.123 \\
\hline In-hospital death & $538(13.3)$ & $11857(14.8)$ & 0.905 & $0.835-0.981$ & 0.015 \\
\hline
\end{tabular}

$P$ values are Pearson's chi-square test (2-tailed). RR indicates relative risk, CI confidence interval

thrombolytic treatment is influenced by distance to the treatment facility and delays in presentation. Up to $50 \%$ of rural stroke patients present late to the treatment facility so that their baseline neuroimaging will already demonstrate established infarction, excluding them from hyperacute treatment. ${ }^{10}$ Second, stroke syndromes usually affect older patients who might have personal directives arguing against aggressive interventions or even transient life-supporting treatment. In our study younger patients were transferred more frequently to stroke centers and older patients were more likely treated in community hospitals. Third, transfer is not risk-free and the benefit of a transfer must be weighed against the possible acute risks of medical deterioration during transfer. Fourth, although hemorrhagic stroke types are less common, intracerebral and subarachnoid hemorrhages in our study were more likely to be transferred to a comprehensive stroke center than other stroke subtypes. This is probably due to the potential need for neurosurgical or intensive care intervention. Fifth, throughout Canada established bypass protocols in most regions mean that stroke patients are brought directly to primary and comprehensive stroke centers, bypassing smaller community hospitals. These result in fewer patients eligible for transfer, a trend that has been observed in other reports that compare outcome before and after the implementation of bypass agreements.

Although we cannot comment on the indications for transfer initiation in our study, comprehensive stroke centers can benefit from direct viewing of neuroimaging to determine which patients are less likely to benefit from and require transfer. This could lead to optimization of transportation-related costs and resource use. For these cases, televideoconsultations with hospitalists at community hospitals that include recommendations for medical care such as blood pressure goals and treating patients on an intermediate care unit may be a viable alternative to transfer. ${ }^{11}$

Mechanical thrombectomy is now the standard of care for ischemic strokes caused by proximal anterior circulation occlusion. ${ }^{12}$ Each of the recently published endovascular trials relied on advanced and pre-established stroke systems of care mandating rapid identification, triaging, imaging and initiation of treatment/transfer. ${ }^{13}$ The ESCAPE trial, which included 11 major centers in Canada, enrolled the first patient in February 2013, mid-way through our analysis period. The trials have underscored the need for faster and better access to comprehensive stroke centers for patients with the diagnosis of acute stroke. The Madrid Stroke Network found that no safety concerns have been indicated for patients with acute ischemic stroke who are transferred between hospitals to undergo reperfusion therapies. Their study also showed for the first time that the frequency of futile transfers for potential endovascular treatment was $\sim 41 \%$. The most common reason for determining that a transfer was futile was clinical improvement; the second most common was exclusion from endovascular treatment due to the results of a second neuroimaging study performed. ${ }^{14}$ This again underscores the need for speed, with onset-to-reperfusion time as the new bottom-line process metric to achieve favorable clinical outcomes. ${ }^{15}$ This new treatment option will likely result in a substantive increase in acute transfers to centers equipped with an angiography suite and staffed with stroke neurologists and interventional neurologists. On the other hand, we know that clinical outcomes are more favorable at high-volume centers and it might therefore be a better strategy to transport the patient, if feasible, directly to a specialized center. The higher cost of transfers compared to direct admission, as well as the delay in final treatment initiation (i.e. mechanical thrombectomy) also support this strategy. ${ }^{16,17}$ Optimal regional algorithms for direct admission vs. transfer in the new era of endovascular therapy still need to be determined. These algorithms will need to incorporate that timely access to IV thrombolysis is still achievable for eligible patients within 4.5 hours from symptom onset with a target door-to-needle-time of less than 60 minutes for

Table 4: Discharge destination by transfer pathways

\begin{tabular}{|c|c|c|c|c|c|c|}
\hline \multirow[b]{2}{*}{ Transfer pathway } & \multicolumn{6}{|c|}{ Discharge destination } \\
\hline & Home & Rehabilitation & Community Care & Home Care & Long-term Care & In-hospital Death \\
\hline Community hospital to community hospital & $11(6.5 \%)$ & $5(3.0 \%)$ & $17(10.1 \%)$ & $25(14.9 \%)$ & $61(36.3 \%)$ & $26(15.5 \%)$ \\
\hline Community hospital to stroke centre & $18(2.0 \%)$ & $19(2.1 \%)$ & $224(25.0 \%)$ & $51(5.7 \%)$ & $318(35.5 \%)$ & $112(12.5 \%)$ \\
\hline Stroke centre to community hospital & $146(8.9 \%)$ & $131(8.0 \%)$ & $349(21.3 \%)$ & $182(11.1 \%)$ & $429(26.1 \%)$ & $265(16.1 \%)$ \\
\hline Stroke centre to stroke centre & $38(2.9 \%)$ & $39(2.9 \%)$ & $222(16.8 \%)$ & $87(6.6 \%)$ & $477(36.0 \%)$ & $135(10.2 \%)$ \\
\hline
\end{tabular}


90\% of treated patients, as per Canadian best practice recommendations. ${ }^{9}$

Strengths of our study are the population-based approach with high external validity and a large sample size of more than 80,000 patients. We cannot comment on the timing of presentation to the hospital, the presenting stroke severity or the modalities of treatment provided at the receiving hospital. Other limitations include the fact that the DAD does not capture patient transfers between an Emergency Department and another facility; it is these types of transfers that would be expected for hyperacute endovascular stroke treatment.

\section{Conclusion}

Patients who were transferred to stroke centers were less likely to die. Further studies are needed to investigate clinical and system predictors to determine who benefits most from transfer and thus avoid increased healthcare costs of unnecessary or futile transfers. Transport pathways might have to be rearranged to ensure a higher proportion of direct admission to a specialized center. Further exploration of the role and utility of transfer is going to be needed specifically for access to endovascular treatment for acute ischemic stroke.

\section{Disclosures}

Charlotte Zerna, Noreen Kamal, M. Patrice Lindsay, Jiming Fang, and Michael Hill do not have anything to disclose.

\section{Statement of Authorship}

C. Zerna contributed to the study concept and design, interpretation of the data, as well as drafting and revising the manuscript.

N. Kamal contributed to the study concept and design, and revising the manuscript.

J. Fang contributed to the data analysis and interpretation as well as revising the manuscript.

P. Lindsay contributed to data acquisition and management, the study concept and design, and revising the manuscript.

M. Hill contributed to the study concept and design, interpretation of the data, as well as drafting and revising the manuscript and functioned as the senior author for this work.

\section{REFERENCES}

1. Niessen LW, Barendregt JJ, Bonneux L, Koudstaal PJ. Stroke trends in an aging population. The Technology Assessment Methods Project Team. Stroke: A Journal of Cerebral Circulation. 1993; 24(7):931-9.
2. Börsch-Supan A. Aging population: Problems and policy options in the US and Germany. Econ Policy. 1991:104-39.

3. Lozano R, Naghavi M, Foreman K, et al. Global and regional mortality from 235 causes of death for 20 age groups in 1990 and 2010: a systematic analysis for the Global Burden of Disease Study 2010. Lancet. 2012;380(9859):2095-128.

4. Mayo NE, Hendlisz J, Goldberg MS, Korner-Bitensky N, Becker R, Coopersmith $\mathrm{H}$. Destinations of stroke patients discarged from the Montreal area acute-care hospitals. Stroke: A Journal of Cerebral Circulation. 1989;20(3):351-6.

5. Fonarow GC, Reeves MJ, Smith EE, et al. Characteristics, performance measures, and in-hospital outcomes of the first one million stroke and transient ischemic attack admissions in get with the guidelines-stroke. Circulation: Cardiovascular Quality and Outcomes. 2010;3(3):291-302.

6. Canadian Institutes for Health Information. Discharge Abstracts Database Metadata. Available from: https://www.cihi.ca/en/ types-of-care/hospital-care/acute-care/dad-metadata.

7. Kokotailo RA, Hill MD. Coding of stroke and stroke risk factors using international classification of diseases, revisions 9 and 10. Stroke: A Journal of Cerebral Circulation. 2005;36(8):1776-81.

8. Canadian Heart and Stroke Foundation. Together against a rising tide: Advancing stroke systems of care. 2014 Stroke Report. 2014.

9. Casaubon LK, Boulanger JM, Blacquiere D, et al. Canadian Stroke Best Practice Recommendations: Hyperacute Stroke Care Guidelines, Update 2015. International Journal of Stroke: Official Journal of the International Stroke Society. 2015;10(6):924-40.

10. Bodechtel U, Barlinn K, Siepmann T, et al. Telestroke care can achieve adequate onset-to-treatment time despite prolonged doorto-needle time. Journal of Stroke and Cerebrovascular Diseases. Submitted.

11. Nguyen C, Mir O, Vahidy F, et al. Resource utilization for patients with intracerebral hemorrhage transferred to a comprehensive stroke center. Journal of stroke and cerebrovascular diseases: the official journal of National Stroke Association. 2015;24(12): 2866-74.

12. European Stroke Organisation. Consensus statement on mechanical thrombectomy in acute ischemic stroke. ESO-Karolinska Stroke Update. 2014.

13. Mocco J, Fargen KM, Goyal M, et al. Neurothrombectomy trial results: stroke systems, not just devices, make the difference. Int J Stroke. 2015;10(7):990-3.

14. Fuentes B, Alonso de Lecinana M, Ximenez-Carrillo A, et al. Futile interhospital transfer for endovascular treatment in acute ischemic stroke: the Madrid Stroke Network experience. Stroke: A Journal of Cerebral Circulation. 2015;46(8):2156-61.

15. Hill MD, Goyal M, Demchuk AM. Endovascular stroke therapy-a new era. International Journal of Stroke: Official Journal of the International Stroke Society. 2015;10(3):278-9.

16. Gupta R, Horev A, Nguyen T, et al. Higher volume endovascular stroke centers have faster times to treatment, higher reperfusion rates and higher rates of good clinical outcomes. Journal of Neurointerventional Surgery. 2013;5(4):294-7.

17. McNeill L, English SW, Borg N, Matta BF, Menon DK. Effects of institutional caseload of subarachnoid hemorrhage on mortality: a secondary analysis of administrative data. Stroke: A Journal of Cerebral Circulation. 2013;44(3):647-52. 